\title{
The flavonoid Baohuoside-I inhibits cell growth and downregulates survivin and cyclin D1 expression in esophageal carcinoma via $\beta$-catenin-dependent signaling
}

\author{
LIFANG WANG ${ }^{1}, \mathrm{AN} \mathrm{LU}^{2}$, XIAOXIA LIU ${ }^{3}$, MEIXIANG SANG ${ }^{4}$, \\ BAOEN SHAN $^{4}$, FANRU MENG ${ }^{1}$, QING CAO ${ }^{1}$ and $\mathrm{XIN} \mathrm{JI}^{1}$
}

\begin{abstract}
${ }^{1}$ Laboratory Department, The Second Hospital of Hebei Medical University, Shijiazhuang, Hebei 050000; ${ }^{2}$ Research Center, Hebei Province Center For Disease Prevention and Control, Shijiazhuang, Hebei 050021; ${ }^{3}$ Department of Biotechnology, Medical College of Hebei University of Engineering, Handan, Hebei 056029; ${ }^{4}$ Tumor Research Institute, The Fourth Hospital of Hebei Medical University, Shijiazhuang, Hebei 050017, P.R. China
\end{abstract}

Received May 19, 2011; Accepted June 27, 2011

DOI: $10.3892 / o r .2011 .1400$

\begin{abstract}
Esophageal cancer is one of the most common malignancies and is associated with a dismal prognosis. Although treatment options have increased for some patients, overall progress has been modest. Thus, there is a great need to develop new treatments. We found that Baohuoside-I, a flavonoid extracted from a Chinese medicinal plant, exhibits anticancer activity. Here, we demonstrated that Baohuoside-I significantly inhibited Eca109 human esophageal squamous carcinoma cell proliferation and induced Eca109 cell apoptosis in vitro and in vivo. The growth inhibitory effect of Baohuoside-I on the Eca109 tumor cell line was examined by MTT assay; the induction of apoptosis was analyzed by flow cytometry. Eca109-luc cells were injected into the subcutaneous tissue of nude mice to establish xenograft tumors. Our results revealed that Baohuoside-I caused a dose- and timedependent inhibition of cell growth and an induction of apoptosis. Furthermore, Baohuoside-I-treated cells were characterized by decreased expression of the $\beta$-catenin gene and protein in the total cell lysates. Thus, the gene and protein expression of the downstream elements survivin and cyclin D1 was downregulated. To determine the precise inhibitory mechanisms involved, further in-depth in vivo studies of Baohuoside-I are warranted. Our study provides the first evidence that Baohuoside-I inhibits tumor growth and induces apoptosis by inhibiting $\beta$-catenin-dependent signaling pathways. Thus, Baohuoside-I is a potential candidate in ESCC disease therapy.
\end{abstract}

Correspondence to: Dr Baoen Shan, Research Center, The Fourth Hospital of Hebei Medical University, Shijiazhuang, Hebei 050017, P.R. China

E-mail: baoenshan@hotmail.com

Key words: Baohuoside-I, esophageal cancer cells, $\beta$-catenin, nude mouse xenograft

\section{Introduction}

Esophageal cancer is one of the most common cancers and one of the main causes of cancer-related death in the world $(1,2)$. Cancer of the esophagus is associated with a very poor survival rate. Even in the most developed countries, the 5-year survival rate ranges merely from 10 to $16 \%$ (3). In China, the mortality rate of esophageal cancer is ranked fourth among all cancer-related deaths, and esophageal squamous cell carcinoma (ESCC) is the major histological type $(4,5)$. Despite significant advances in screening, surgical care and chemoradiotherapy techniques, the prognosis for patients with ESCC remains poor $(6,7)$. Thus, it is necessary to search for new treatment strategies.

Herbal and natural products are valuable resources for anticancer drugs (8). Plant-derived active constituents and their semi-synthetic and synthetic analogs have served as one of the major sources for new anticancer drugs $(9,10)$. Several plantderived anticancer agents, such as flavopiridol, acronycine, bruceantin and thalicarpine, are currently being used in clinical trials in the US (10). Thus, natural products have been the mainstay of cancer chemotherapy for the past few decades (10).

Recently, by screening hundreds of traditional Chinese medicines, we found that extracts of Cortex periplocae (CP) possess cancer-preventative properties. CP is the dry root of the traditional Chinese herb Periploca sepium Bunge, referred to as Xiangjiapi in Chinese. It is a traditional type of medicine commonly used for a variety of clinical effects, including antiinflammation, enhancing bones and muscles and stimulating the nervous system (11). Itokawa et al first found that periplocoside A from CP markedly inhibited the growth of ascite cancer S180 cells (12). Baohuoside-I $\left(\mathrm{C}_{27} \mathrm{H}_{30} \mathrm{O}_{10}\right.$, MW: 514; Fig. 1), a flavonoid extracted from $\mathrm{CP}$, has been found to significantly inhibit the growth of esophageal cancer, leukemia and breast cancer cells (13-15). However, the molecular mechanism of this extract has yet to be elucidated.

Aberrant Wnt signaling has been reported to contribute to various human diseases including ESCC (16). The Wnt signaling pathway plays a central role in numerous cellular 


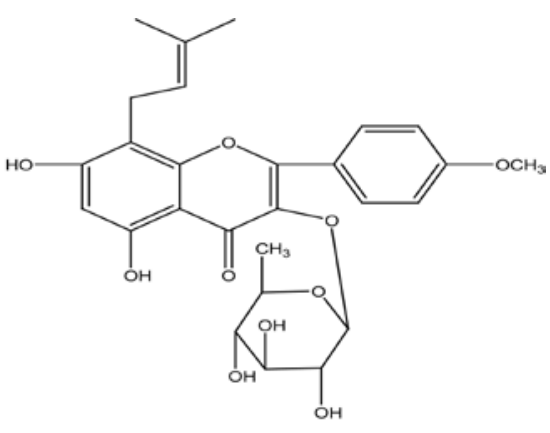

Figure 1. Chemical structure of Baohuoside-I extracted from Cortex periplocae. $\mathrm{C}_{27} \mathrm{H}_{30} \mathrm{O}_{10}$; MW 514

processes starting from embryonic development to tissue/organ homeostasis in adults. $\beta$-catenin is a key component of this pathway, performing a dual function: a component of cell-cell adhesion and a transcriptional activator in conjunction with T-cell factor/lymphoid enhancer factor (TCF/LEF) transcription factors (17). The cellular levels of $\beta$-catenin are tightly regulated by a multiprotein destruction complex consisting of Adenomatous polyposis coli (APC), axin and glycogen synthase kinase $3 \beta$ (GSK-3 $\beta$ ) (18). Aberrant activation of $\beta$-catenin, mostly due to mutation(s) in APC, confers oncogenic potential by activating several target genes of the Wnt/ $\beta$-catenin pathway such as cyclin D1 and survivin (19). A fraction of esophageal squamous cell carcinomas has abnormal nuclear accumulation of $\beta$-catenin accompanied with increased cyclin D1 expression (20). In addition, the level of $\beta$-catenin mRNA expression is a new prognostic marker for ESCC (21). Overall, an aberrant activation of $\beta$-catenin-dependent signaling has a major contribution in the pathogenesis of ESCC, and therefore, targeting this pathway may have vital implications in controlling the progression of this malignancy. Herein, we studied the possible efficacy and associated mechanisms of Baohuoside-I against the human esophageal squamous cell carcinoma Eca109 cell line. For the first time, we showed that, Baohuoside-I inhibits the growth of Eca109 cells in vitro as well as in vivo through the downregulation of $\beta$-catenin signaling.

\section{Materials and methods}

Chemical substances. Baohuoside-I extracted from Cortex periplocae ( $>96 \%$ purity) (identified by Professor Ren, New Drug Research and Development Co., Ltd., North China Pharmaceutical Corp., Shijiazhuang, China) was dissolved in dimethylsulfoxide (DMSO) (Sigma Co., Germany) and diluted to final concentrations in each culture medium used as described below. Cells cultured in medium only were considered as the vehicle control group.

Cell lines and cell culture. Human esophageal squamous cell carcinoma Eca109 cells (Cellular Biology Institute of the Shanghai Academy of Sciences, Shanghai, China) were maintained in RPMI-1640 (Gibco) containing 10\% fetal calf serum (Sijiqing, Hangzhou, China), $100 \mathrm{U} / \mathrm{ml}$ penicillin, $100 \mu \mathrm{g} / \mathrm{ml}$ phytomycin (Invitrogen, USA) at $37^{\circ} \mathrm{C}$ in an incubator with a humidified atmosphere of $5 \% \mathrm{CO}_{2}$. After $\sim 80 \%$ confluence, the cultured cells were digested using $0.25 \%$ trypsin (Amresco, USA) and subcultured.
Cell viability assay. The effect of Baohuoside-I on cancer cell viability was determined using the MTT assay. The cells were plated at $1 \times 10^{4}$ per well in $100 \mu \mathrm{l}$ of complete culture medium and treated with $3.125,6.25,12.5,25.0$ and $50.0 \mu \mathrm{g} / \mathrm{ml}$ concentrations of Baohuoside-I in 96-well microtiter plates (Costar, USA). Each concentration of Baohuoside-I was repeatedly used in 10 wells. After incubation for 24,48 and $72 \mathrm{~h}$ at $37^{\circ} \mathrm{C}$ in a humidified incubator, MTT [ $5 \mathrm{mg} / \mathrm{ml}$ in phosphate-buffered saline (PBS)] was added to each well, and cells were incubated for $4 \mathrm{~h}$. The plate was then centrifuged at 1,500 x $\mathrm{g}$ for $5 \mathrm{~min}$. After careful removal of the medium, $0.1 \mathrm{ml}$ of buffered DMSO was added to each well to dissolve the blue insoluble MTT formazan produced by mitochondrial succinate dehydrogenase, and the plates were shaken. The absorbance was recorded on a microplate reader (Titertek Multiskan, North Ryde, Austria) at a wavelength of $570 \mathrm{~nm}$. The effect of Baohuoside-I on growth inhibition was assessed as the percentage of cell viability when the vehicle-treated cells were concurrently $100 \%$ viable.

Analysis of apoptosis. Quantification of apoptotic cells was performed using propidium iodide (PI) (Sigma, St. Louis, MO, USA) staining according to the manufacturer's instructions. Briefly, cells were treated with various concentrations of Baohuoside-I $(0-50 \mu \mathrm{g} / \mathrm{ml})$ for $48 \mathrm{~h}$, then collected and resuspended in $500 \mu \mathrm{l}$ PBS containing $50 \mathrm{mg} / \mathrm{ml} \mathrm{PI}, 0.1 \%$ Triton $\mathrm{X}-100,0.1 \mathrm{mmol} / 1 \mathrm{EDTA}(\mathrm{Na})_{2}$ and $50 \mu \mathrm{g} / \mathrm{ml} \mathrm{RNase}$. After incubation in the dark for $30 \mathrm{~min}$, analysis was performed with a FACS flow cytometer (Becton-Dickinson, Sunnyvale, CA, USA) with Ex = $488 \mathrm{~nm}$ and $\mathrm{Em}=530 \mathrm{~nm}$, using Cell Quest software. Cells in sub-G0 peak were regarded as apoptotic.

Western blot analysis. Western blot analysis was performed on Eca109 cells for the presence of $\beta$-catenin, survivin and cyclin D1. Cell lysates were prepared using $700 \mu \mathrm{l}$ cell lysis buffer [0.05 M Tris- $\mathrm{HCl}$ (pH 7.4), $0.15 \mathrm{M} \mathrm{NaCl}, 1 \%$ Nonidet $\mathrm{P}-40,0.5 \mathrm{M}$ PMSF, $50 \mu \mathrm{g} / \mathrm{ml}$ aprotinin, $10 \mu \mathrm{g} / \mathrm{ml}$ leupeptin, $50 \mu \mathrm{g} / \mathrm{ml}$ pepstatin, $0.4 \mathrm{mM}$ sodium orthovanadate, $10 \mathrm{mM}$ sodium fluoride and $10 \mathrm{mM}$ sodium pyrophosphate]. The lysate was then sonicated for $20 \mathrm{sec}$, spun at 1,500 x g/min for $10 \mathrm{~min}$, and the supernatant was collected. Protein samples (20-100 $\mu \mathrm{g}$ ) were loaded onto a 10\% SDS-PAGE gel and run at $120 \mathrm{~V}$ for $2 \mathrm{~h}$ and transferred to a nitrocellulose filter (NC filter; Amersham, Arlington Heights, IL, USA) for $2 \mathrm{~h}$ at $135 \mathrm{~mA}$. The membranes were blocked with $5 \%$ milk in TBST overnight, washed three times and incubated with the primary Ab (anti- $\beta$-catenin, anti-survivin and anti-cyclin D1; Santa Cruz Biotechnology) for $2 \mathrm{~h}$ at room temperature. The membranes were washed three times with TBST and incubated for $1 \mathrm{~h}$ with fluorochrome-labeled secondary anti-rabbit IgG (IRDye 800-LI-COR; Odyssey). After four washings with TBST, the membrane was imaged with the LI-COR Odyssey infrared imager.

Reverse transcriptase-polymerase chain reaction (RT-PCR) analysis. Total RNA was extracted from the treated cells using TRI reagent (Sigma) according to the manufacturer's instructions. RT-PCR was conducted as previously described (22), with some modifications. In brief, cDNA was prepared using RNA samples $(3-5 \mu \mathrm{g})$ to which $1 \mu \mathrm{g}$ oligo(dT)18, $0.5 \mathrm{mM}$ dNTP and 200 units of Revert Aid ${ }^{\mathrm{TM}}$ H-Minus M-MuLV RT 
Table I. Primers and conditions used in the reverse transcriptase-polymerase chain reaction.

\begin{tabular}{|c|c|c|c|}
\hline Gene & Primers & Annealing temperature & Cycles \\
\hline$\beta$-catenin & $\begin{array}{l}\text { F: 5'-GAAACGGCTTTCAGTTGAGC-3' } \\
\text { R: 5'-CTGGCCATATCCACCAGAGT-3' }\end{array}$ & $55^{\circ} \mathrm{C}$ & 35 \\
\hline cyclin D1 & $\begin{array}{l}\text { F: 5'-ATGCCAACCTCCTCAACGACC-3' } \\
\text { R: 5'-TGGCACAGAGGGCAACGAAGG-3' }\end{array}$ & $55^{\circ} \mathrm{C}$ & 35 \\
\hline Survivin & $\begin{array}{l}\text { F: 5'-CGGCATGGGTGCCCCGACGTTG-3' } \\
\text { R: 5'-TTGAGGCCTCTGGCCGGAGC-3' }\end{array}$ & $55^{\circ} \mathrm{C}$ & 38 \\
\hline$\beta$-actin & $\begin{array}{l}\text { F: 5'-ATCTGGCACCACACCTTCTACAATGAGCTGCG-3' } \\
\text { R: 5'-CGTCATACTCCTGCTTGCTGATCCACATCTGC-3' }\end{array}$ & $55^{\circ} \mathrm{C}$ & 35 \\
\hline
\end{tabular}

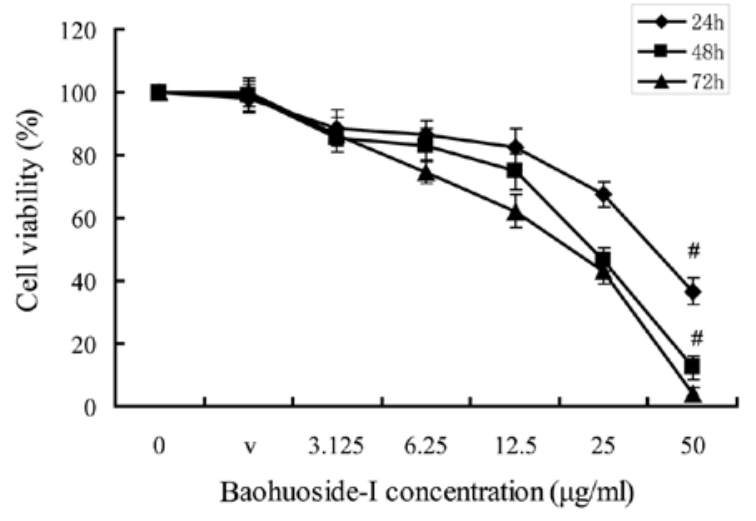

Figure 2. Baohuoside-I inhibits the growth of human Eca109 cells. Cells were plated overnight and treated with $12.5-50 \mu \mathrm{g} / \mathrm{ml}$ Baohuoside-I for 24-72 h. A the end of treatment, cell viability was determined by the MTT assay. Data shown are the mean $\pm \mathrm{SD} .{ }^{\#} \mathrm{P}<0.01$ compared with the control.

enzyme were added (MBI Fermentas, USA). PCR analysis was performed using selective primers (Table I) (synthesized at Sangon, Shanghai, China), and $2 \mu \mathrm{l}$ of RT product was incubated with 1 unit of Taq DNA polymerase in a $50-\mu 1$ reaction mixture containing $1 \mathrm{mM}$ dNTP and $1.5 \mathrm{mM} \mathrm{MgCl}$ (Promega, USA). The amplified fragments were detected in $1.5 \%(\mathrm{w} / \mathrm{v})$ agarose gel and analyzed using an IS1000 image analysis system (Alpha Innotech, San Leandro, CA, USA).

Establishment of stably-tagged Eca109-luc cell lines. The parental Eca109 cells were stably transduced with firefly luciferase by using an identified recombinant plasmid expressing firefly luciferase. Briefly, the plasmid of pGL4.17 [luc2/ puro]-cmv (Zongmed Corporation, US) was transfected into Eca109 cells by using the Lipofectamine (Invitrogen) method. Pooled stable cells were selected with puromycin $(1.0 \mu \mathrm{g} / \mathrm{ml})$ for 7 days. Luciferase activity was assessed by detection of photons using the Xenogen IVIS system (Xenogen, USA) after administration of $150 \mu \mathrm{g} / \mathrm{ml}$ D-luciferin to cells incubated 2 min after administration of the substrate.

Xenograft tumor model of human esophageal squamous cell carcinoma. The use and care of animals were carried out by following the guidelines approved by the Institutional Animal Care and Use Committee. Female Balb/c nude mice (4- to 6-weeks-old) were obtained from the Animal Research Center of the Chinese Academy of Medical Science (Beijing, China). Subconfluent Eca109-Luc cells were harvested and resuspended in PBS to a final density of $2 \times 10^{7}$ cells $/ \mathrm{ml}$. Prior to injection, cells were resuspended in PBS and analyzed by $0.4 \%$ trypan blue exclusion assay (viable cells $>90 \%$ ). For subcutaneous injection, $\sim 1 \times 10^{6}$ Eca109-Luc cells in $200 \mu$ l PBS were injected into the left flank of each mouse using $27 \mathrm{G}$ needles. At 1 week after tumor cell injection, Baohuoside-I $(25 \mathrm{mg} / \mathrm{kg}$ per mouse) was injected intralesionally once a day, whereas the 10 mice intended for vehicle treatment were administered an equal volume of PBS.

Xenogen bioluminescence imaging. Small animal whole body optical imaging was carried out as described (23-25). Briefly, mice were anesthetized with isoflurane attached to a nosecone mask equipped with the Xenogen IVIS imaging system (Zongmed Corporation, USA) and subjected to imaging weekly after subcutaneous injection. For imaging, mice were injected (i.p.) with D-Luciferin sodium salt (Gold Biotechnology, St. Louis, MO) at $100 \mathrm{mg} / \mathrm{kg}$ body weight in $0.1 \mathrm{ml}$ sterile PBS. Acquired pseudo-images were obtained by superimposing the emitted light over the grayscale photographs of the animal. Quantitative analysis was carried out with Xenogen's Living Image V2.50.1 software as described (23-25). Animals were sacrificed after 3 weeks, and tumor samples were retrieved for histological evaluation and Western blot analysis.

Histological evaluation. Retrieved tumor tissues were fixed in $10 \%$ formalin and embedded in paraffin. Serial sections of the embedded specimens were stained with hematoxylin and eosin (H\&E).

Statistical analysis. All quantitative experiments were performed in triplicate and/or repeated 3 times. Data are expressed as the mean \pm standard deviation (SD). Statistical significant differences between vehicle treatment vs. drug-treatment were determined by one-way ANOVA and the t-test. $\mathrm{p}<0.05$ was considered to indicate statistical significance.

\section{Results}

Baohuoside-I inhibits the growth of Ecal09 cells. As shown in Fig. 2, Baohuoside-I significantly inhibited the growth of 


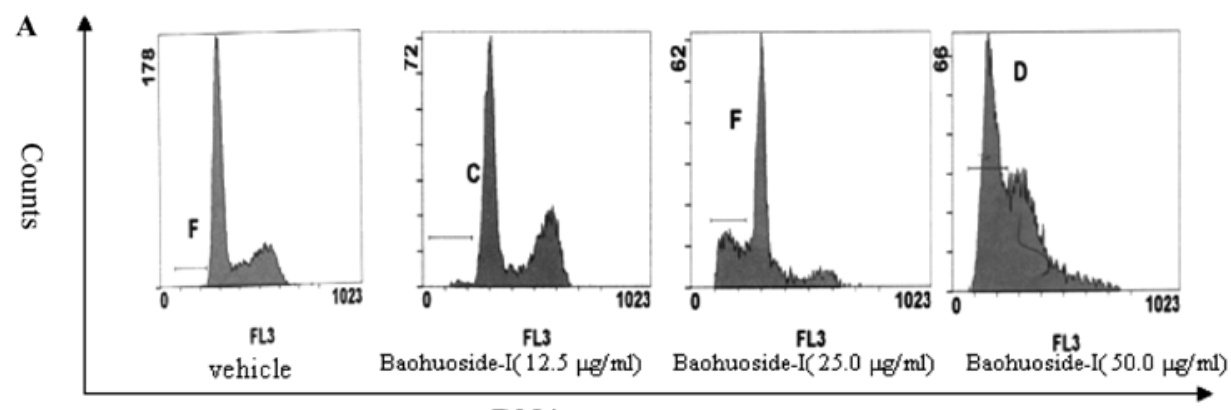

DNA content

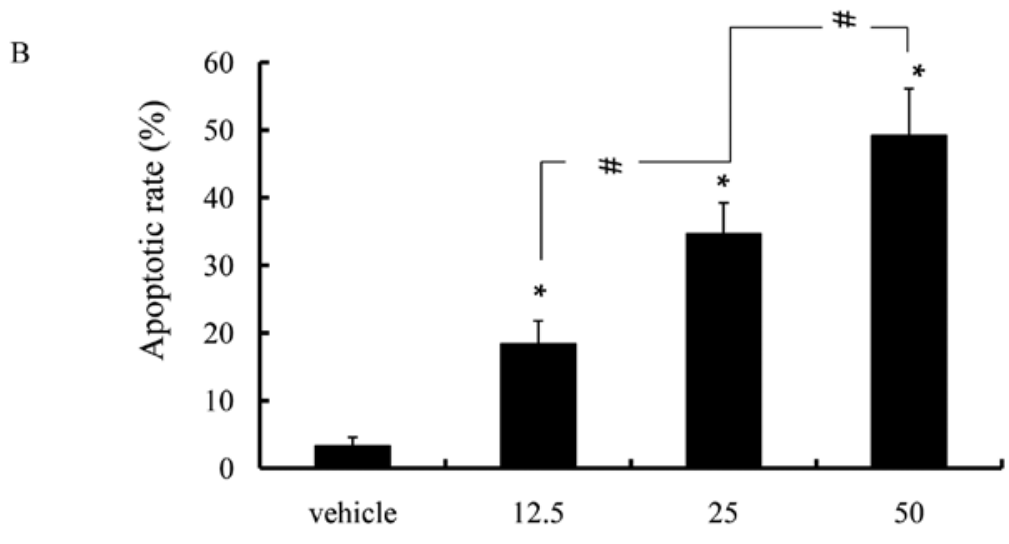

Baohuoside-I concentration $(\mu \mathrm{g} / \mathrm{ml})$

Figure 3. Effect of Baohuoside-I on the apoptosis of Eca109 cells treated with various concentrations of Baohuoside-I (0-50 mg/ml) for $48 \mathrm{~h}$. (A) The cells were stained with PI, and the total DNA content was measured to analyze the apoptotic rate (in the sub-G1 peak) by flow cytometry. (B) The apoptotic rate of the cells was analyzed by Mod Fit LT 3.0. Bars, mean of three independent plates. ${ }^{*} \mathrm{P}<0.01$, compared to the control group $(0 \mathrm{~h}) ;{ }^{*} \mathrm{P}<0.01$, comparison between the two groups.

A
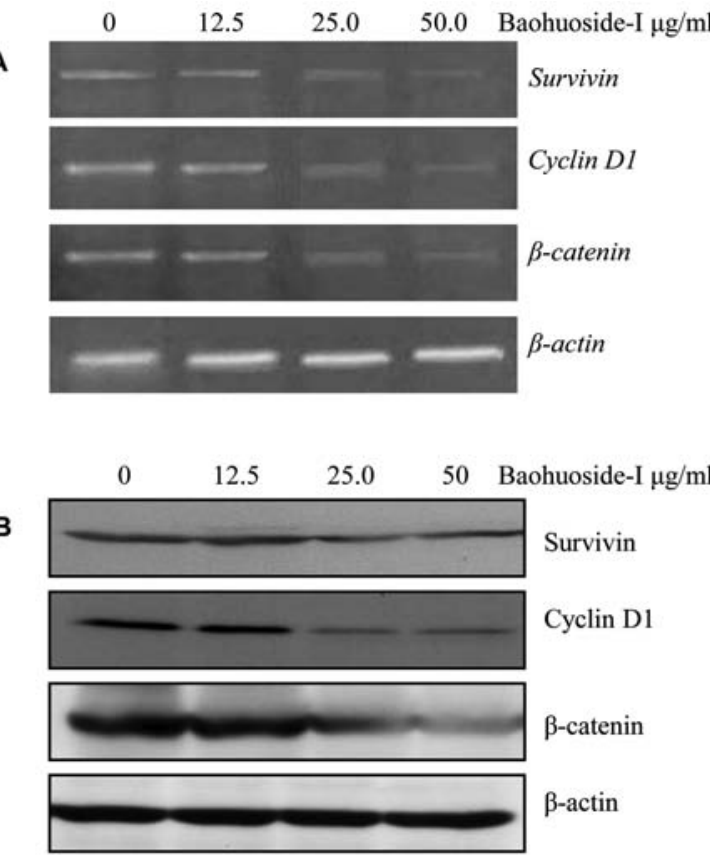

Figure 4. Baohuoside I inhibits $\beta$-catenin downstream gene expression in Eca109 cells in a dose-dependent manner. (A) Eca109 cells were treated with Baohuoside I for $48 \mathrm{~h}$, and mRNA expression of the $\beta$-catenin target genes survivin and cyclin DI was detected by RT-PCR. (B) The whole-cell extracts were resolved using 10-12\% sodium dodecyl sulfate-polyacrylamide gel electrophoresis. Protein expression levels were examined using specific antibodies for $\beta$-catenin, cyclin D1 and survivin by Western blot analysis. Shown are representatives of three independent experiments. esophageal squamous cell carcinoma Eca109 cells in a doseand time-dependent manner. Cells barely grew in the presence of $50.0 \mu \mathrm{g} / \mathrm{ml}$ Baohuoside-I. IC $_{50}$ values at $48 \mathrm{~h}$ were $24.8 \mu \mathrm{g} /$ $\mathrm{ml}$. The results demonstrated the potency of Baohuoside-I in inhibiting the growth of esophageal squamous cell carcinoma cells in vitro.

Baohuoside-I treatment increases the rate of apoptosis in Eca109 cells. To further detect apoptotic processes, the level of apoptosis in the Baohuoside-I-treated Eca109 cells was determined using PI staining. A dose-dependent increase in the cell population in the sub-G1 phase of the cell cycle was noted (Fig. 3A). Baohuoside-I (50 $\mu \mathrm{g} / \mathrm{ml})$ dramatically induced cell apoptosis; $49.21 \%$ after $48 \mathrm{~h}$ of Baohuoside-I treatment compared with $3.26 \%$ in the control cells (Fig. 3B).

Baohuoside-I inhibits $\beta$-catenin activity and decreases the expression of downstream $\beta$-catenin-transcriptional targets. $\beta$-catenin-mediated signaling regulates a diverse set of genes responsible for cell proliferation, differentiation and homeostasis (26-28). To scrutinize which downstream factor accounts for the cell apoptosis induced by Baohuoside-I, we examined the expression levels of the factors, including survivin and cyclin D1. As shown in Fig. 4 , the expression levels of $\beta$-catenin, survivin and cyclin D1 mRNA and proteins were significantly decreased in the Baohuoside-I-treated cells compared to the vehicle-treated cells, which was consistent with the apoptotic effect induced by Baohuoside-I. 
B

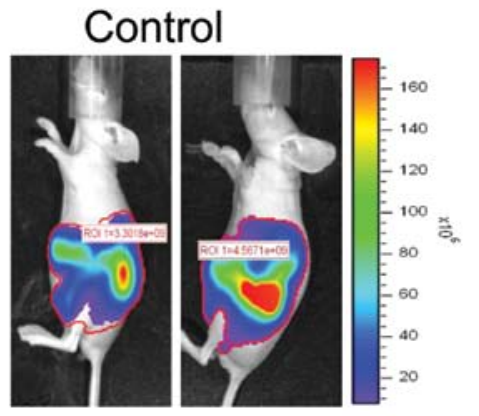

Baohuoside-I
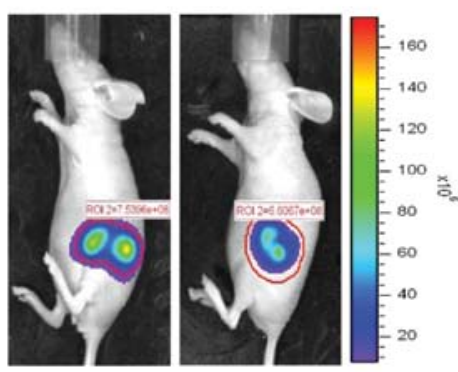

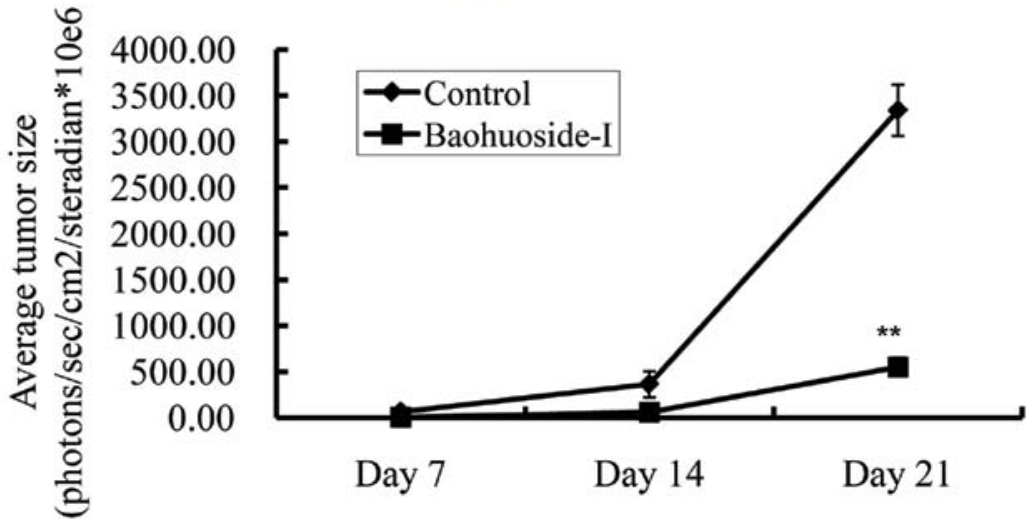

Control

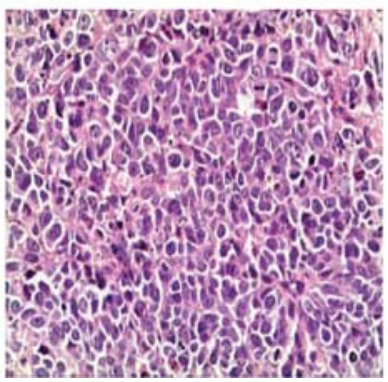

\section{Baohuoside-I}

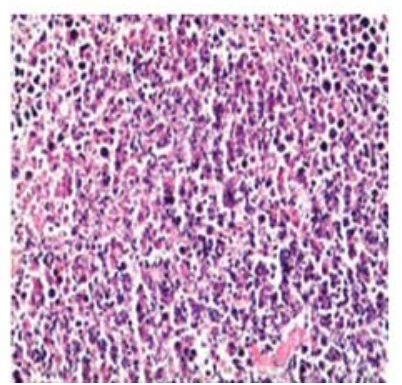

Figure 5. Baohuoside-I inhibits in vivo tumor growth in a xenograft tumor model of human esophageal cancer cells. (A) Tumor growth was monitored using Xenogen bioluminescence imaging. Exponentially growing firefly luciferase-tagged Eca109 cells were injected into the left flank of Balb/c nude mice (1x10 ${ }^{6}$ cells/injection site). One week after cancer cell injection, Baohuoside-I was intralesionally administered ( $25 \mathrm{mg} / \mathrm{kg}$ body weight, once a day). Mice were subjected to Xenogen bioluminescence imaging on a weekly basis. Representative Xenogen imaging results at week 3 are shown. (B) Quantitative analysis of Xenogen bioluminescence imaging data. Acquired weekly imaging data were analyzed as described in Materials and methods. Average tumor size was represented by imaging signal intensities (in photons/sec/steradian). ${ }^{* *} \mathrm{p}<0.01$. (C) Histological evaluation of xenograft tumor samples. Retrieved tumor samples were fixed, embedded and subjected to H\&E staining. Representative images are shown (magnification, $\mathrm{x} 400$ ).

Baohuoside-I inhibits in vivo tumor growth in a xenograft tumor model of human esophageal cancer cells. We investigated the in vivo anticancer activity of Baohuoside I using a xenograft model of human esophageal squamous cell carcinoma cells. Briefly, exponentially growing firefly luciferase-tagged Eca109 cells were injected into the flanks of $\mathrm{Babl} / \mathrm{c}$ nude mice. One week after cancer cell injection, Baohuoside-I was intralesionally administered $(25 \mathrm{mg} / \mathrm{kg}$ body weight, once a day). Mice were subjected to Xenogen bioluminescence imaging on a weekly basis for an additional three weeks. As shown in Fig. 5, the Baohuoside-I treatment group exhibited a significantly decreased Xenogen imaging signal when compared with the control group. In fact, quantitative analysis revealed that Baohuoside-I-mediated inhibition of xenograft tumor growth was statistically significant $(\mathrm{p}<0.01)$ at three weeks after treatment, even though the tumors were not completely eliminated (Fig. 5A and B). Histologic analysis (H\&E staining) indicated that the Baohuoside-I treatment group exhibited a decreased cellularity in the tumor mass (Fig. 5C).

Baohuoside-I decreases $\beta$-catenin, cyclin DI and survivin expression in human Ecal09 tumorxenografts. Overexpression of $\beta$-catenin and its downstream target proteins is commonly observed in human Eca109 tumor xenografts. To ascertain in vivo effect of Baohuoside-I on the expression of $\beta$-catenin and its downstream target molecules, Eca109 xenograft tissues from the control and Baohuoside-I-treated groups were also analyzed by Western blot analysis for $\beta$-catenin, cyclin D1 and survivin protein levels. As shown in Fig. 6, Baohuoside-Itreated $(25 \mathrm{mg} / \mathrm{kg}$ body weight) xenografts showed a $40 \%$ $(\mathrm{P}<0.01)$ decrease in the $\beta$-catenin protein levels compared 
A

Control Baohuoside-l $25 \mathrm{mg} / \mathrm{kg}$

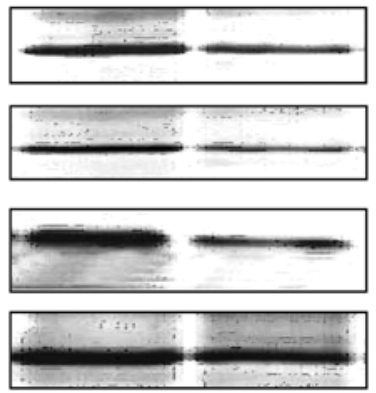

Survivin

Cyclin D1

$\beta$-catenin

$\beta$-actin

B

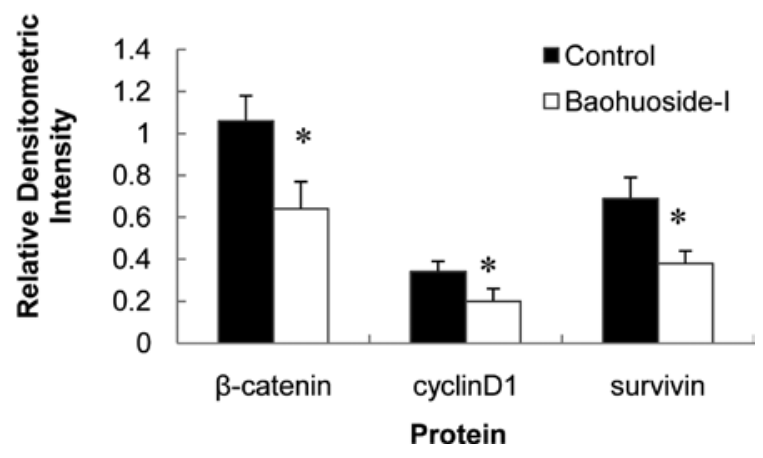

Figure 6. Baohuoside-I suppresses the expression of survivin, cyclin D1 and $\beta$-catenin in xenografted tumor tissue treated with Baohuoside-I. Retrieved tumor samples treated with Baohuoside-I were prepared and subjected to Western blot analysis. Shown are representatives of independent experiments. ${ }^{*} \mathrm{P}<0.01$, compared with the control group.

with the vehicle control. A similar effect of Baohuoside-I on cyclin D1 and survivin expression was also observed; a 41 $(\mathrm{P}<0.01)$ and $45 \%(\mathrm{P}<0.01)$ decrease respectively was noted when compared with the control. Together, these findings suggest that downregulation of $\beta$-catenin levels and consequent signaling may be a potential in vivo mechanism by which Baohuoside-I inhibits Eca109 tumor growth in nude mice.

\section{Discussion}

We investigated the molecular mechanism underlying the anticancer activity of a medicinal plant product Baohuoside-I in human esophageal carcinoma. Although the treatment options for esophageal cancer have substantially increased, and substantial benefits have been achieved for some patients, overall progress has been more modest than had been hoped (29). Thus, there is a great clinical need to develop new treatment regimens. Recently, we found that a flavonoid from a Chinese medicinal plant, Baohuoside-I, exhibits significant anticancer activity. Yet, the molecular mechanism that underlies its anticancer activity is not fully understood.

Here, we elucidated the anti-proliferative activity of Baohuoside-I and explored the mechanism involved in the inhibition of proliferation of esophageal cancer. A significant growth inhibition of Eca109 cells was noted throughout the entire period of the experiment compared to cells propagated in the growth medium. Flow cytometric analysis of the Baohuoside-I-treated cells demonstrated an increase in apoptotic cells, suggesting that Baohuoside-I plays a key role in the apoptosis of Eca109 cells. At the molecular level, Baohuoside I downregulates $\beta$-catenin, the key protein of the $\mathrm{Wnt} / \beta$-catenin signaling pathway, and expression of its downstream target molecules survivin and cyclin D1 in esophageal carcinoma invitro and in vivo. Thus, downregulation of $\beta$-catenin signaling by Baohuoside-I appears to exert an important role in inhibiting the proliferative capacity of Eca109 cells.

In normal mature cells, the Wnt pathway regulates normal cellular activities. Most $\beta$-catenin within cells binds to E-cadherin on the cell membrane to form a complex-epidermal catenin and cadherin unit (ECCU). Free $\beta$-catenin is degraded and polyubiquitinated after binding to a protein complex consisting of molecules, such as APC, to regulate cellular proliferation, differentiation and adhesion. Once the Wnt pathway is activated by abnormal expression of oncogenes, anti-oncogenes and cellular adhesion molecules, $\beta$-catenin is accumulated in the cytoplasm without degradation, and translocated into the nucleus, where it binds to Tcf/Lef and initiates transcription of its target genes such as cyclin D1, resulting in cellular canceration $(26,30)$. The $\beta$-catenin oncogenic protein is widely expressed in many human malignancies (31) including ESCC (32), head and neck squamous cell carcinoma (33-35) and colorectal cancer (36). Moreover, it has been reported that elevated $\beta$-catenin levels promote early neoplastic change through oncogenic signaling within cells $(17,37)$. Thus, targeting the oncogenic protein $\beta$-catenin can enhance chemotherapy outcome against solid human cancers (38).

Our studies and other previous studies have shown that quercetin, one of the most common flavonoids, inhibits human SW480 colon cancer growth in association with the regulation of the $\beta$-catenin/Tcf signaling pathway $(39,40)$. Poly E, a well-standardized green tea catechin mixture, was found to inhibit the proliferation of aerodigestive adenocarcinoma cells and to immortalize Barrett's epithelial cells and this inhibition was correlated with the downregulation of the cyclin D1 protein and nuclear $\beta$-catenin level (41). The present study demonstrated that Baohuoside-I induces the inhibition of proliferation and apoptosis of Eca109 cells by modulating the $\beta$-catenin signaling pathway. Our results showed that Baohuoside-I significantly reduced $\beta$-catenin expression at the transcriptional and protein level.

One of the downstream targets of $\beta$-catenin transcriptional activity involved in cell cycle regulation is cyclin D1, a key molecule facilitating the progression of cells through the G1 checkpoint $(42,43)$. Cyclin D1 appears to be an independent predictor of ESCC patient outcome (44). Another downstream target of this pathway is survivin, which is a member of the inhibitor of apoptosis family proteins. Survivin is thought to be a bifunctional regulator of cell death and proliferation expressed during embryonic development, while it is undetectable in healthy adult tissues but is re-expressed in a number of types of cancer, including esophageal cancer (45-49). We observed a decreased expression of both cyclin D1 and survivin by Baohuoside-I, suggesting their possible role in the observed growth-inhibitory effects of Baohuoside-I in Eca109 cells.

To further substantiate in vitro the growth-inhibitory effects of Baohuoside-I on human Eca109 cells, we extended our studies to in vivo conditions by implanting Eca109-luc 
tumor xenografts in athymic nude mice. Baohuoside-I injection significantly inhibited the growth of Eca109-luc tumor xenografts, which was accompanied by a decrease in the levels of $\beta$-catenin and its downstream targets, cyclin $\mathrm{D} 1$ and survivin, consistent with the results of the in vitro experiment. Tumorigenesis is a complex interrelated multistep process. Inhibition of any step in this process may lead to the disruption of tumorigenesis and may serve as a potential antitumor therapy. In the present study, we demonstrated that Baohuoside-I suppressed Eca109 cell proliferation and induced apoptosis, suggesting that Baohuoside-I affected tumorgenesis through targeting the $\beta$-catenin signaling pathway leading to apoptosis and the inhibition of growth of esophageal cancer cells. This may be explained by the modulation of $\beta$-catenin mediated by downregulation of its downstream elements, cyclin D1 and survivin. In conclusion, we demonstrated for the first time that Baohuoside-I is a novel active antitumor consituent of a Chinese medicinal plant. The findings of the present study underscore the efficacy of Baohuoside-I against ESCC with translational potential in the future.

\section{Acknowledgements}

This study was supported by the National Natural Science Foundation of China (grant no. 30772752). We thank all the members of the laboratory of Dr BE. Shan, Research Center, The Fourth Hospital of Hebei Medical University. We also thank the New Drug Research and Development Co., Ltd., North China Pharmaceutical Corporation, China for their support.

\section{References}

1. Parkin DM, Bray F, Ferlay J and Pisani P: Global Cancer Statistics, 2002. CA Cancer J Clin 55: 74-108, 2005.

2. Munro AJ: Oesophageal cancer: a view over overviews. Lancet 364: 566-568, 2004

3. Sant M, Allemani C, Santapuilani M, Knijn A, Marchesi F and Capocaccia R: EUROCARE-4. Survival of cancer patients diagnosed in 1995-1999. Results and commentary. Eur J Cancer 45: 931-991, 2009

4. Zou XN, Chen WQ, Zhang SW, Li LD, Lu FZ and Chen YH: An analysis of esophageal cancer incidence and mortality from 30 cancer registries in China, 1998-2002. China Cancer 161: 142-146, 2007.

5. Stoner GD and Gupta A: Etiology and chemoprevention of esophageal squamous cell carcinoma. Carcinogenesis 22 $1737-1746,2001$

6. Besharat S, Jabbari A, Semnani S, Keshtkar A and Marjani J: Inoperable esophageal cancer and outcome of palliative care. World J Gastroenterol 14: 3725-3728, 2009.

7. Alibakhshi A, Aminian A, Mirsharifi R, Jahangiri Y, Dashti H and Karimian F: The effect of age on the outcome of esophageal cancer surgery. Ann Thorac Med 4: 71-74, 2009.

8. Cragg GM, Grothaus PG and Newman DJ: Impact of natural products on developing new anti-cancer agents. Chem Rev 109: 3012-3043, 2009.

9. Koehn FE and Carter GT: The evolving role of natural products in drug discovery. Nat Rev Drug Discov 4: 206-220, 2005.

10. Mann J: Natural products in cancer chemotherapy: past, present and future. Nat Rev Cancer 2: 143-148, 2002.

11. National Committee of Pharmacopeia: Pharmacopoeia of the People's Republic of China, Chemical Industry Publishing Company, Beijing, p181, 2005 (In Chinese).

12. Itokawa $\mathrm{H}, \mathrm{Xu} \mathrm{JP}$ and Takeya K: Studies on chemical constituents of an antitumor fraction from Periploca sepium. V. Structures of new pregnane glycosides, periplocosides J, K, F and O. Chem Pharm Bull 36: 4441-4446, 1998.

13. Zhang J, Shan BE and Liu GS: Apoptosis induced by ethyl acetate extract from Cortex periplocae in human breast cancer cell line MCF-7. Tumor 26: 418-421, 2006 (In Chinese).
14. Zhao LM, Shan BE, Ai J, Ren FZ and Lian YS: Effects of periplocin from Cortex periplocae on proliferation of human esophageal carcinoma cells TE-13 and related mechanisms. Tumor 28: 203-206, 2008 (In Chinese).

15. Wang LF, Shan BE, Liu LH, Ren FZ and Shan TQ: Effect of Baohuoside-I from Cortex periplocae on proliferation and apoptosis of esophageal carcinoma cells. Tumor 29: 123-126, 2009 (In Chinese)

16. Lv J, Cao XF, Ji L, Zhu B, Tao L and Wang DD: Association of Wnt1/3-catenin with clinical pathological characteristics and prognosis of esophageal squamous cell carcinoma. Genet Test Mol Biomarkers 14: 363-369, 2010.

17. DasGupta R, Kaykas A, Moon RT and Perrimon N: Functional genomic analysis of the Wnt-wingless signaling pathway. Science 308: 826-833, 2005.

18. Xie D, Zeng YX, Wang HJ, Wen JM, Tao Y and Sham JS: Expression of cytoplasmic and nuclear survivin in primary and secondary human glioblastoma. Br J Cancer 94: 108-114, 2006.

19. Tetsu $\mathrm{O}$ and Frank MC: $\beta$-catenin regulates expression of cyclin D1 in colon carcinoma cells. Nature 398: 422-426, 1999.

20. Kudo J, Nishiwaki T, Haruki N, et al: Aberrant nuclear localization of $\beta$-catenin without genetic alterations in $\beta$-catenin or Axin genes in esophageal cancer. World J Surg Oncol 5: 21-29, 2007.

21. Ji L, Cao XF, Wang HM, et al: Expression level of beta-catenin is associated with prognosis of esophageal carcinoma. World $\mathbf{J}$ Gastroenterol 13: 2622-2625, 2007.

22. Liu LH, Wang SJ, Shan BE, Shao L, Sato A and Kawamura K: IL-27-mediated activation of natural killer cells and inflammation produce antitumor effects for human esophageal carcinoma cells. Scand J Rheumatol 68: 22-29, 2008.

23. He BC, Chen L, Zuo GW, et al: Synergistic antitumor effect of the activated PPARgamma and retinoid receptors on human osteosarcoma. Clin Cancer Res 16: 2235-2245, 2010.

24. Luo X, Chen J, Song WX, et al: Osteogenic BMPs promote tumor growth of human osteosarcomas that harbor differentiation defects. Lab Invest 88: 1264-1277, 2008.

25. Su Y, Luo X, He BC, et al: Establishment and characterization of a new highly metastatic human osteosarcoma cell line. Clin Exp Metastasis 26: 599-610, 2009.

26. Utsunomiya T, Doki Y, Takemoto H, et al: Correlation of betacatenin and cyclin D1 expression in colon cancers. Oncology 61: 226-233, 2001

27. Thevenod $\mathrm{F}$ and Chakraborty PK: The role of Wnt/beta-catenin signaling in renal carcinogenesis: lessons from cadmium toxicity studies. Curr Mol Med 10: 387-404, 2010.

28. Doucas H, Garcea G, Neal CP, Manson MM and Berry DP: Changes in the Wnt signalling pathway in gastrointestinal cancers and their prognostic significance. Eur J Cancer 41: 365-379, 2005.

29. Wu T, Yang X, Zeng X and Eslick GD: Traditional Chinese medicinal herbs in the treatment of patients with esophageal cancer: a systematic review. Gastroenterol Clin North Am 38: 153-167, 2009.

30. Nelson WJ and Nusse R: Convergence of Wnt, $\beta$-catenin, and cadherin pathways. Science 303: 1483-1487, 2004.

31. Giles RH, van Es JH and Clevers H: Caught up in a Wnt storm: Wnt signaling in cancer. Biochim Biophys Acta 1653: 1-24, 2003.

32. Situ DR, Hu Y, Zhu ZH, Wang J, Long $H$ and Rong TH: Prognostic relevance of $\beta$-catenin expression in T2-3N0M0 esophageal squamous cell carcinoma. World J Gastroenterol 16: 5195-5202, 2010 .

33. Yang F, Zeng Q, Yu G, Li S and Wang CY: Wnt/beta-catenin signaling inhibits death receptor-mediated apoptosis and promotes invasive growth of HNSCC. Cell Signal 18: 679-687, 2006.

34. Goto M, Mitra RS, Liu M, et al: Rap1 stabilizes beta-catenin and enhances beta-catenin-dependent transcription and invasion in squamous cell carcinoma of the head and neck. Clin Cancer Res 16: 65-76, 2010.

35. Tsai YP, Yang MH, Huang CH, et al: Interaction between HSP60 and beta-catenin promotes metastasis. Carcinogenesis 30: 1049-1057, 2009.

36. Morin PJ, Sparks AB, Korinek V, et al: Activation of beta-cateninTcf signaling in colon cancer by mutations in beta-catenin or APC. Science 275: 1787-1790, 1997.

37. Dilek FH, Topak N, Tokyol C, Akbulut G and Dilek ON: $\beta$-catenin and its relation to VEGF and cyclin D1 expression in pT3 rectosigmoid cancers. Turk J Gastroenterol. 21: 365-371, 2010.

38. Saifo MS, Rempinski DR Jr, Rustum YM and Azrak RG: Targeting the oncogenic protein beta-catenin to enhance chemotherapy outcome against solid human cancers. Mol Cancer 9: 310-320, 2010. 
39. Shan BE, Wang MX and Li RQ: Quercetin inhibits human SW480 colon cancer growth in association with inhibition of cyclin D1 and survivin expression through Wnt/ $\beta$-catenin signaling pathway. Cancer Invest 27: 604-612, 2009.

40. Park CH, Chang JY, Hahm ER, Park S, Kim HK and Yang CH: Quercetin, a potent inhibitor against $\beta$-catenin/Tcf signaling in SW480 colon cancer cells. Biochem Biophys Res Commun 328: 227-234, 2005

41. Song S, Krishnan K, Liu K and Bresalier RS: Polyphenon $\mathrm{E}$ inhibits the growth of human Barrett's and aerodigestive adenocarcinoma cells by suppressing cyclin D1 expression. Clin Cancer Res 15: 622-631, 2009.

42. Behrens J: Control of $\beta$-catenin signaling in tumor development. Ann NY Acad Sci 910: 21-33, 2000.

43. Fu M, Wang C, Li Z, Sakamaki T and Pestell RG: Minireview: cyclin D1: normal and abnormal functions. Endocrinology 145: 5439-5447, 2004.

44. LinDC, Du XL and Wang MR: Protein alterations in ESCC and clinical implications: a review. Dis Esophagus 22: 9-20, 2004.
45. Ambrosini G, Adida C and Altieri DC: A novel anti-apoptosis gene, survivin, expressed in cancer and lymphoma. Nat Med 3: 917-921, 1997.

46. Yie SM, Lou B, Ye SR, et al: Clinical significance of detecting survivin-expressing circulating cancer in patients with non-small cell lung cancer. Lung Cancer 63: 284-290, 2009.

47. Vallbohmer D, Kuhn E, Warnecke-Eberz U, et al: Failure in down-regulation of intratumoral survivin expression following neoadjuvant chemoradiation in esophageal cancer. Pharmacogenomics 9: 681-690, 2008.

48. Kim PJ, Plescia J, Clevers H, Fearon ER and Altieri DC: Survivin and molecular pathogenesis of colorectal cancer. Lancet 362: 205-209, 2003

49. Ma H, Nguyen C, Lee KS and Kahn M: Differential role for the coactivators $\mathrm{CBP}$ and $\mathrm{p} 300$ on TCF/B-catenin-mediated survivin gene expression. Oncogene 24: 3619-3631, 2005. 